\title{
Clifford Geertz: La interpretació de les cultures, PUV, València, 2013, 458pp.
}

Els tòpics generats sobre aspectes culturals del model social vigent impedeixen de reflexionar sobre el significat de conceptes que demanen superar l'esquematisme i el mecanicisme monocausal. Les interpretacions antopològiques, algunes dels quals poden ser susceptibles de ser aplicades a les relacions entre societat i educació, aporten elements de treball per a plantejar definicions i anàlisis de referents socioculturals que ens són coetanis.

La interpretació de les cultures (1973), conjunt de quinze treballs publicats entre 1957 i 1973 per l'antropòleg nord-americà, exponent de l'antropologia simbòlica, Clifford Geertz (1926-2006) tracta temàtiques aparentment diverses: nacionalisme, religió, cultura, símbols sagrats, ritus, ideologia, dimensió política de la cultura. Amb tot, la diversificació de recerques no impossibilita plantejar, com a característica comuna, el significat de la cultura, com a complex d'imaginaris, a partir del quefer de l'antropòleg materialitzat en les etnografies. Aquesta finalitat és tractada en el primer capítol del volum -"Descripció densa: cap a una teoria interpretativa de la cultura"l'objectiu del qual és demanar-se pel sentit del treball de camp i plantejar el model d'anàlisi de l'autor.

La conclusió a la qual arriba Geertz és que la cultura és un document interpretat que explica la conducta, els procediments, com a acció simbòlica. Cal, doncs, assumir la necessitat de comprendre el contingut dels llenguatges d'un grup humà, ja que així podrem adaptar-nos-hi. Aquesta, i no cap altra, és la raó per la qual cal descriure en assaigs el que observem. Ara bé, l'observació participant, que l'autor valora pel que suposa de relació directa amb l'objecte d'estudi, no ha de suposar distorsió de la unitat d'anàlisi. L'antropòleg no estudia des de l'abstracció, estudia des del lloc on s'estableix i conviu.

L'aportació semiòtica d'aquest antropòleg especifica que la "cultura consisteix en estructures de significat socialment establertes". Per a explicar aquesta finalitat Geertz ens remet a una reflexió del filòsof Wittgenstein sobre el fet que una persona pot arribar a ser un enigma per a una altra, atès que no és entesa. No existeix cap comportament que sigui arbitrari, sinó que el que aquest especifica és la seva racionalitat segons el context, el patró de vida al qual representa. Aquesta és una observació normativa que l'antropòleg (i el sociòleg i l'historiador) no ha de perdre mai de vista, perquè, contràriament, pot remetre a explicacions desubstancialitzades, 
allunyades del marc de referència que explica cada cultura. Tota el plantejament del volum, doncs, tracta sobre l'actitud del recercador pel que fa a escatir l'estructura del significat d'un codi cultural. I qui diu d'un codi cultural, diu d'una religió i d'una ideologia.

En conseqüència, la metodologia comprensiva geertziana (l'antropòleg basteix fonamentalment una metodologia basada en la interpretació) especifica una altra qüestió fonamental: "la comprensió de la cultura d'un poble exposa la seua normalitat sense reduir la seua particularitat". L'al•legat contra el tic cosmopolita identificació de la internacionalitat/internacionalització amb un fals mundialisme multicultural fonamentat en la retòrica suposadament "antinacionalista" dels estats 'nacionals' convencionals- hi és palès: cap identitat social no ha de dissoldre's en cap altre context que pugui ser legitimat com a superior (sic). 'Particularitat', tal com és entesa en el text, equival a personalitat, autonomia/ autodeterminació, i es contraposa a 'interferència'/ superposició de referents, llengües i cultures.

En conclusió, quina és la 'descripció densa' que ha d'elaborar l'antropòleg? "El que significa -proposa Geertz- és que les descripcions de la cultura berber, jueva o francesa s'han de fer en termes de les construccions que imaginem que fan servir els berbers, els jueus o els francesos per a viure, les fórmules que ells utilitzen per a definir allò que els succeeix". La imaginació, doncs, no esdevé 'invent', ni relativisme, sinó que implica esforç per a elaborar un relat que des de la subjectivitat (no pas des del subjectivisme) permeti de 'posar-nos en lloc' de l'altre per a identificar el que mou (xarxes de relacions socials) i explica un pràctica determinada. L'exercici, però, sempre suposa una aproximació a una cultura determinada. Una aproximació, mai a una totalitat-en si, perquè mai no arribem a pertànyer-hi. En aquest esforç comprensiu cal bandejar tot el capital de prejudicis i de supremacismes.

El resultat d'aquesta tasca és la monografia, que resulta ser una ficció, és a dir, una elaboració sobre allò que hem observat, i que ha d'expressar el pensament dels protagonistes obervats. Amb la constatació del que es diu no és suficient, sinó que el treball ha de concretar el que els participants enuncien. Amb tot, reconeix Geertz, hem de ser conscients que estandarditzem una part del significat, que és el contingut que ens transmeten els informadors. I és a partir d'aquesta limitació, que es contraposa a l'eclecticisme, que hem de plantejar reflexions significatives i extreure generalitzacions contrastables. Per aquest motiu cal no establir la rigorositat d'una interpretació pel seu abast extensiu, sinó per la capacitat de delimitar -fer-ne rellevant l'àmbit d'aplicació- d'intensificar una anàlisi que serveixi per a entendre un "món conceptual" determinat.

Les grans teories poden no ser explicatives de res. Com reconeix Geertz: "les grans contribucions teòriques no sols es basen en estudis específics, sinó que és molt difícil abstreure-les d'aquests estudis i integrar-les en alguna cosa que es pogués anomenar 'teoria cultural'". El que sí que cal destacar és que la concreció no implica absència de generalització categorial. La teoria ha de conceptualitzar per a decodificar l'acció simbòlica que roman en una cultura. Què ens diu una representació sobre la vida 
d'un col•lectiu? Aquesta finalitat serà assolida si, com especifica Geertz, som capaços de relacionar diversos fenòmens $i$ aplicar-hi una metodologa que integri diversos enfocaments, que per a aquest autor poden anar des de la biologia a la sociologia i la psicologia. La integració de resultats n'és l'objectiu.

Si l'ètim antropologia equival a 'discurs, raonament, sobre allò humà', el que proposa la metodologia qualitativa de Geertz és estudiar tots els fenòmens que hi convergeixen, siguin materials o ideals, però tenint com a comú denominador un sistema referencial. L'esment de Gertz a la concepció sobre la religió del filòsof Georges Santayana (1863-1952) pot servir per a situar aquesta darrera observació: "cada religió viva i sa té una idiosincràsia marcada. El seu poder consisteix en el seu mssatge especial i sorprenent i en la inclinació que la revelació dóna a la vida. Les perspectives que obre i els misteris que proposa són un altre món en el qual viure; i un altre món en el qual viure -tant si esperem viure-hi eternament com si no- és el significa tenir una religió".

Demanar-nos pels significats des de cada context teòric objecte d'estudi duu a superar descontextualitzacions que arriben a prendre la part pel tot.

Xavier Ferré Trill. Departament de Pedagogia. Universitat Rovira i Virgili. 